\title{
Comparing Different Systemic Risk Measures for European Banking System
}

\author{
Annalisa Di Clemente ${ }^{1}$ \\ ${ }^{1}$ Department of Social and Economic Sciences, Sapienza University of Rome, Italy. \\ Correspondence: Annalisa Di Clemente, Department of Social and Economic Sciences, Sapienza University of \\ Rome, Italy.
}

Received: November 7, 2018

Accepted: November 27, 2018 Online Published: December 6, 2018

doi:10.5539/ibr.v12n1p35

URL: https://doi.org/10.5539/ibr.v12n1p35

\begin{abstract}
This research examines and compares the performances in terms of systemic risk ranking for three different systemic risk metrics based on daily frequency publicly available data, specifically: Marginal Expected Shortfall (ES), Component Expected Shortfall (CES) and Delta Conditional Value-at-Risk ( $\Delta$ CoVaR). We compute $\triangle$ CoVaR, MES and CES by utilizing EVT principles for modelling marginal distributions and Student's $t$ copula for describing the dependence structure between every bank and the banking system. Our objective is to attest whether different systemic risk metrics detect the same banks as systemically dangerous institutions with refer to a sample of European banks over the time span 2004-2015. For each bank in the sample we also calculate three traditional market risk measures, like Market VaR, Sharpe's beta and the correlation between every bank and the banking system (European STOXX 600 Banks Index). Another aim is to explore the existence of a link among systemic risk measures and traditional risk metrics. In addition, the classification results obtained by the different risk metrics are compared with the ranking in terms of systemic riskiness (for European banks) calculated by Financial Stability Board (2015) using end-2014 data and collected in its list of Global Systemically Important Banks (G-SIBs). With refer to the entire sample period, we find a good coherence of ranking results among the three different systemic risk metrics, in particular between CES and $\triangle \mathrm{CoVaR}$. Moreover, we find for MES and $\triangle \mathrm{CoVaR}$ a strong linkage with beta and correlation metrics respectively. Finally, CES metric shows the highest level of concordance with the list of G-SIBs by FSB with refer to European banks.
\end{abstract}

Keywords: systemic risk ranking, European banking system, Marginal Expected Shortfall, Delta Conditional Value-at-Risk, Component Expected Shortfall, copula function, Extreme Value Theory

JEL classification: G17, G21, C63

\section{Introduction}

Currently the debate on worldwide financial stability constitutes a key concern not only for academics but also for regulatory authorities and international institutions (International Monetary Fund [IMF], 2009).

The last global financial crisis highlighted the concepts such as systemic risk and contagion effect and, consequently, the need of a macro prudential approach to regulation and supervision on financial institutions, especially cross-border ones. Limiting systemic risk appeared as a possible way to prevent forthcoming systemic financial crises as it allows to contain the domino effect taking down financial institutions one after the other (Basel Committee on Banking Supervision [BCBS], 2010).

Consistent with this approach, each institution should have a surplus of capital according to the negative externalities it generates, or in other words in relation to its contribution to the risk of the global financial system.

Financial Stability Board (FSB) issues a list of banks denominated as Systemically Important Banks (SIB), the so-called Global-SIBs. The ranking judgements of the FSB stem from a method founded on balance-sheet figures (BCBS, 2011; 2013).

Since these data are not publicly available, the reasons behind the Authority's decisions do not always appear clear and transparent to financial markets and operators.

Because of these weaknesses, the researchers (Acharya, Engle, \& Richardson, 2012; Acharya, Pedersen, Philippon \& Richardson, 2017; Adrian \& Brunnermeier, 2011; 2016; Banulescu \& Dumitrescu, 2013; Benoit, 
Colletaz, Hulin, \& Pérignon, 2013; Brownlees \& Engle, 2012; Brownlees \& Engle, 2017; Karimalis \& Nomikos, 2018) suggested alternative approaches founded on market data (equity returns) for recognizing the SIBs in an acceptable and verifiable manner.

Coherently with the aim above, we analyze and compare the performances in terms of systemic risk ranking of three different systemic risk measures based on daily frequency publicly available data, in particular: Marginal Expected Shortfall (ES), Component Expected Shortfall (CES) and Delta Conditional Value-at-Risk ( $\Delta$ CoVaR).

Our first purpose is to attest whether these different systemic risk measures identify the same banks as systemically important financial institutions with refer to a sample of 25 European banks included in the European Banking Index from January 1, 2004 to January 8, 2015.

In addition, we calculate for every bank in the sample three traditional market risk measures, like market Value-at-Risk (VaR), Sharpe (1964) beta and the correlation between every bank and European banking system.

Our second objective is to verify the existence of a linkage among systemic risk metrics and traditional risk measures.

Moreover, the riskiness of every bank in the sample has been assessed over four different time horizons: the total period (from January 1, 2004 to January 8, 2015); the crisis period (from July 2, 2007 to May 15, 2009); the worst day (October 30, 2008); the pre-crisis period (from January 1, 2004 to June 30, 2007). The analyzed entire time span includes the latest financial crisis.

In addition, in this research, $\triangle \mathrm{CoVaR}$ is measured by an original approach (Di Clemente, 2018) founded on Extreme Value Theory (EVT) for modelling the marginal distributions and on the proprieties of Student's $t$ copula function for defining the dependence framework between the system and every bank in the sample.

Following the original idea by Hakwa, Jäger-Ambrożewicz and Rüdiger (2015) that suggested a general analytical formula for CoVaR founded on copula functions, Di Clemente (2018) extends this analytical structure by utilizing univariate EVT, a probabilistic method valuable for representing extreme events in a financial context (Embrechts, Klüppelberg, \& Mikosch, 1997).

We underline that Hakwa et al. (2015) offered a flexible structure for estimating CoVaR that takes into account some significant observed features for marginal losses as skewness, fat tails and interdependence properties like linear, non-linear and positive or negative tail dependence.

Taking into account the analytical estimate outcomes in Di Clemente (2018), in this research we estimate $\triangle$ CoVaR by Student's t copula and EVT. In fact, Di Clemente (2018) used a backtesting technique for assessing the performance of every investigated couple copula-marginal distribution. In particular, the author verifies that the approach founded on Student's-t copula and EVT margin produces the best fitting to real data with respect to the other analytical representations (five different copula functions: Normal, Student's-t, Clayton, Gumbel and Frank; and three different assumptions for marginal distributions: Normal, Student's-t, EVT).

Moreover, in order to estimate MES and CES metrics, in this research we utilize Monte Carlo Simulation for obtaining a large number of scenarios for the log returns of financial institutions. Coherently with the CoVaR approach followed in this work, also for measuring MES and CES we utilize EVT principles for modelling margins and Student's t copula (Sklar, 1959; 1996) for describing the dependence between every bank and the system (Nelsen, 1998).

At our knowledge, currently these advanced methodologies have never been utilized all together for assessing the contribution of each bank to system instability.

For our empirical analysis, we utilize daily returns of the STOXX Europe 600 Banks Index and of 25 European banks included in the European Banking Index from January 1, 2004 to January 8, 2015. We use the STOXX Europe 600 Banks Index as a proxy of the European banking system. The choice of the 25 banks among the 49 in the Index (March, 2015) has been conditioned by the availability of equity returns over the analysed total time horizon.

Furthermore, the classification results obtained by the different risk metrics are compared with the ranking in terms of systemic riskiness (for European institutions) calculated by Financial Stability Board (November 2015) using end-2014 data and collected in its list of global systemically important banks (G-SIBs). We use the list of G-SIBs published by Financial Stability Board (November 2015) as a benchmark for analyzing which risk metric can best reproduce it (if we assume the truthfulness of the FSB's list).

The remaining paper is organized as follows. Section 2 offers a brief review of systemic risk metrics utilized in this study, underlying in particular the strengths and the weaknesses of each measure. Section 3 offers an 
analytical explanation of the systemic risk metrics: MES, CES and $\triangle \mathrm{CoVaR}$. Section 4 explains the advanced methodologies implemented for computing the three different systemic risk metrics and describes the financial data set utilized for empirical analysis. Section 5 describes and comments in detail the main empirical results. In particular, these outcomes refer to systemic risk rankings for European banks in the sample based on different systemic risk metrics and different traditional risk measures (alternatively). Section 6 summarizes the most interesting findings of this research and concludes.

\section{A Brief Review of Systemic Risk Metrics}

MES is the Marginal Expected Shortfall metric introduced by Acharya et al. (2017); it represents the marginal contribution of an institution to systemic risk as measured by the Expected Shortfall $\left(\mathrm{ES}_{\mathrm{s}}\right)$ of the system. MES is computed as the first derivative of the financial system risk (measured by its Expected Shortfall, $\mathrm{ES}_{\mathrm{s}}$ ) with respect to an institution's position (defined as the weight of institution's market capitalization in the market capitalization of the whole financial system).

MES reflects the sensitivity of the financial system tail risk to a unit change in an institution's position, namely to its relative size. In other words, MES measures the increase in the tail risk of the system induced by a marginal increase in the weight of the single institution in the system.

Originally proposed by Acharya et al. (2017), MES was extended to a conditional version by Brownlees and Engle (2012). By definition, the ES at the $\alpha \%$ level is the expected return in the worst $\alpha \%$ (from $1 \%$ to $5 \%$ typically) of the cases, but it can be extended to the general case in which the returns exceed a given threshold $\mathrm{C}$.

In conclusion, $\mathrm{MES}_{\mathrm{i}}$ represents the marginal contribution of the single institution $\mathrm{i}$ to the tail loss of the whole financial system. The basic idea is that the institutions with the highest MES values contribute the most to market drops; thus, these institutions appear as the greatest drivers of systemic risk.

However, the main drawback of MES is that a small and unlevered institution can appear as more dangerous for the financial system than a big and levered one (Banulescu \& Dumitrescu, 2013).

In addition, Benoit et al. (2013) find a strong positive relationship between MES and institution beta for a sample of top financial US institutions over the period 2000-2010. According to Benoit et al. (2013), this result implies that systemic risk ranking of financial institutions based on MES may reflect ranking obtained by ordering institutions on the traditional systematic (or market) risk measure of Sharpe's beta.

For overcoming this disadvantage, Acharya, Engle and Richardson (2012) and Brownlees and Engle (2017) extend the MES metric for taking into account nominal measures such as the liabilities and the leverage of the institution and propose the SRISK metric.

SRISK corresponds to the expected capital shortfall of the financial institution conditional to a crisis affecting the whole financial system. Following this metric, the institutions with the largest capital shortfall are considered the greatest contributors to crisis of financial system and, consequently, the most systemically dangerous institutions.

On the other hand, these nominal indicators (liabilities and leverage) are subject to availability problems, especially at a high (daily) frequency.

Because of all these problems, Banulescu and Dumitrescu (2013) suggest a new and simple alternative method to identify systemically important institutions, such as a component approach. Precisely, the authors propose a new systemic risk measure called Component Expected Shortfall (CES) for quantifying the contribution of each single institution to the overall risk, given that the financial system tail risk is measured by $\mathrm{ES}_{\mathrm{s}}$.

According to the definition of Banulescu and Dumitrescu (2013), CES measures the absolute contribution of an institution to the risk of the whole financial system (as opposed to the marginal contribution). It is obtained by calibrating the first derivative of the ES (for the system) using weights defined for each financial institution. Therefore the systemic riskiness of every financial institutions at a given date $t$ is assessed by measuring each institution's contribution to the financial system's expected loss measured by ES. The larger the contribution, the more systemically important the institution.

CES metric depends both on the firm's size, given by its market capitalization relative to that of the entire financial system, and on the expected loss of the institution when the whole system is in a stress scenario. This new systemic risk measure allow us to select the riskiest financial firms on the market by directly ranking the institutions according to their riskiness.

In addition, Adrian and Brunnermeier $(2011 ; 2016)$ propose a co-risk metric, likely the CoVaR. This metric lets us to incorporate the dependence structure between every bank and the system in the systemic risk evaluation. 
The authors expressed CoVaR as the Value-at-Risk (VaR) of the system conditional to the event of extreme losses for a single bank. The prefix "Co" of CoVaR means conditional, contagion or co-movement trying to take into account spillover risks among banks. Consequently, the quantitative framework of CoVaR is based on the conditional distribution of a random variable, $X_{\mathrm{s}, t}$, representing the (loss of) whole system, $\mathrm{s}$, given the distress of a single bank, $i$, represented by a random variable $\mathrm{X}_{\mathrm{i}, \mathrm{t}}$.

By using this risk metric, it is possible to assess the marginal contribution of every institution to systemic risk, that is Delta Conditional Value-at-Risk ( $\Delta \mathrm{CoVaR}) . \Delta \mathrm{CoVaR}$ is the difference $(\Delta)$ between the CoVaR of the system conditional to the distress of that institution and its CoVaR conditional to the "normal" state of the same institution.

In other words, $\triangle \mathrm{CoVaR}$ measures the contribution of every bank to the instability of the whole system.

Adrian and Brunnermeier $(2011 ; 2016)$ underline as $\triangle \mathrm{CoVaR}$ is not equivalent to VaR; in particular they report a weak relationship between the market tail risk of an institution measured in isolation by its $\mathrm{VaR}$, and the $\triangle \mathrm{CoVaR}$ of the same institution.

Also Benoit et al. (2013) find a weak linkage between the market VaR of each institution and its contribution to systemic risk, measured by its $\triangle \mathrm{CoVaR}$. In particular, their empirical studies on US financial sector over the period 2000-2010 confirm as systemic risk ranking of US financial institutions based on $\Delta$ CoVaR does not mirror ranking obtained by ordering institutions on market VaR.

\section{Analytical Definition of Systemic Risk Measures}

\subsection{CoVaR and $\triangle \mathrm{CoVaR}$}

Consider a random variable $X_{i, t}$ representing the returns of a generic financial institution i at time $\mathrm{t}(\mathrm{i}=1, \ldots, \mathrm{N}$; $\mathrm{t}=1, \ldots, \mathrm{T})$. The $\mathrm{VaR}$ of $X_{i, t}$ at the probability level $\alpha \in(0,1)$ is defined as in equation (1):

$$
\operatorname{VaR}_{\alpha, t}^{i}=F_{i, t}^{-1}(\alpha)=\inf \left\{x_{i, t} \in \mathbb{R}: F_{i, t} \geq \alpha\right\}
$$

In equation (1) $F_{i, t}^{-1}$ is the generalized inverse distribution function of the return distribution $F_{i, t}$. We can also represent equation (1) in the following way:

$$
\operatorname{Pr}\left(X_{i, t} \leq \operatorname{VaR}_{\alpha, t}^{i}\right)=\alpha
$$

Adrian and Brunnermeier $(2011 ; 2016)$ defined CoVaR as in the following equation:

$$
\operatorname{Pr}\left(X_{s, t} \leq \operatorname{CoVaR}_{\alpha, \beta, t} \mid X_{i, t}=\operatorname{VaR}_{\alpha, t}^{i}\right)=\beta
$$

Equation (3) denotes the $\beta$-quantile of system returns, $X_{s, t}$ conditional to $X_{i, t}=\operatorname{VaR} R_{\alpha, t}^{i}$.

Formally, $\operatorname{CoVaR}_{\alpha, \beta, t}$ is represented as the $\beta$-quantile of the conditional distribution in equation (3) where $s \neq i$.

The probability levels $\alpha$ and $\beta$ can be fixed by the regulatory authorities. Usually these probability levels are fixed to $1 \%$ or $5 \%$. Currently many works adopt a common probability value for $\alpha$ and $\beta$. In our study, a confidence level of $1 \%$ for $\alpha$ and $\beta$ is assumed.

Adrian and Brunnermeier $(2011 ; 2016)$ defined the contribution of each bank i to systemic risk using $\Delta \mathrm{CoVaR}$ metric. Precisely:

$$
\Delta \operatorname{CoVaR}_{\alpha, \beta, t}=\operatorname{CoVaR}_{\alpha, \beta, t}-\operatorname{CoVaR}_{0.5, \beta, t}
$$

\subsection{MES and CES}

We consider a financial system composed of the banks in the STOXX Europe 600 Banks Index. $X_{\text {st }}$ represents the random variable of the daily $\log$ returns of the European banking sector, $\mathrm{s}$, on day $\mathrm{t}$ (where $\mathrm{t}=1, \ldots, \mathrm{T}$ and $\mathrm{i}=$ $1, \ldots, \mathrm{N}$ ) using the following equation:

$$
X_{s t}=\sum_{i=1}^{N} w_{i t} \cdot X_{i t}
$$

In equation (5) $X_{\mathrm{it}}$ is the daily log return of the $\mathrm{i}$-th bank in the Banking Index and $\mathrm{w}_{\mathrm{it}}$ is its weight.

$\mathrm{MES}_{\mathrm{i}}$ is the marginal contribution of an institution to systemic risk, as measured by the Expected Shortfall (ES) of the system. By definition, ES at the $\alpha \%$ level is the expected return in the worst $\alpha \%$ of the cases, but it can be extended to the general case in which the returns exceed a given threshold $\mathrm{C}$.

In our study, $C$ is equal to the Value-at-Risk of the random variable $X_{\text {st }}$ at the probability level of $1 \%$ over a daily holding period. In this study the crisis event is defined as the situation in which financial system's distress exceeds the $\operatorname{VaR}(1 \%)$. We derive a nonparametric measure of MES by Monte Carlo simulation. The metric of 
MES is calibrated by means of individual weights of each bank in order to obtain CES.

The conditional ES of the system is defined analytically as in equation (6):

$$
E S_{s t}(C)=\mathbb{E}_{t-1}\left(X_{s t} \mid X_{s t}<C\right)
$$

Then, the MES corresponds to the partial derivative of the system ES with respect to the weight of institution i in the financial system. Analytically:

$$
\operatorname{MES}_{i t}(C)=\frac{\partial E S_{s t}}{\partial w_{i t}}=\mathbb{E}_{t-1}\left(X_{i t} \mid X_{s t}<C\right)
$$

MES measures the increase in the risk of the system, measured by ES, induced by the marginal contribution of the institution $i$ to the risk of the financial system. The higher the institution's MES, the higher the individual contribution of the firm to the risk of financial system instability.

CES measures the absolute contribution of an institution to the risk of the whole financial system (as opposed to the marginal contribution). It is achieved by calibrating the first derivative of the ES (for the system) using weights defined for every bank as in equation (8):

$$
C E S_{i t}=w_{i t} \frac{\partial E S_{s t}(C)}{\partial w_{i t}}
$$

In addition, $C E S_{i t}(C)=w_{i t} \mathbb{E}_{t-1}\left(X_{i t} \mid X_{s t}<C\right)$ measures the total contribution of component $\mathrm{i}$ to the overall $\mathrm{ES}$, where $\mathbb{E}_{t-1}\left(X_{i t} \mid X_{s t}<C\right)$ corresponds to the $\operatorname{MES}_{\mathrm{it}}(\mathrm{C})$.

Furthermore, the percentage version of the Component Expected Shortfall (CES\%) can be introduced. $\mathrm{CES} \%_{\mathrm{it}}(\mathrm{C})$ measures the proportion of systemic risk at time t due to institution i. It is calculated as the component loss normalized by the financial system loss.

Precisely, CES\% $\%_{\text {it }}(\mathrm{C})$ risk measure can be immediately computed once the weights $\mathrm{w}_{\mathrm{it}}$ are defined and the conditional expectation $\mathbb{E}_{t-1}\left(X_{i t} \mid X_{s t}<C\right)$ is calculated. While the weights are easily obtained using market capitalization data for all the institutions in the sample, the expected value of institution returns conditional on the market being in stress requires a more complex analysis. For this reason, we use the fact that $\mathbb{E}_{t-1}\left(X_{i t} \mid X_{s t}<\right.$ C) corresponds to the MES.

By equation (7) the systemic riskiness of financial institutions at a given date $t$ can be assessed by measuring each institution contribution to the financial system expected loss measured by ES. The larger the contribution, the more systemically important the institution.

The systemic risk measure of CES is defined as a natural extension of Component Value-at-Risk (Jorion, 2007) to the Expected Shortfall. In portfolio risk management literature we find both marginal and component risk measures. While marginal VaR measures the effect of one unit change in the position of a given component on portfolio risk (measured by portfolio VaR), the component VaR shows how the portfolio VaR would change if the component was removed from portfolio.

In the same way, both type of measures can be utilized to evaluate the systemic risk by measuring the impact of an institution on the financial system risk (measured by system ES). On the other hand, the marginal measure of MES does not take into account the firm size (measured by its relative market capitalization). This characteristic of MES can produce an improper ranking of the institutions in which small and negligible firms appear as SIFI. Differently, the component measure of CES takes explicitly into account the size of the institutions in the systemic risk measurement by following the logic of the too-big-to-fail (Banulescu \& Dumitrescu, 2013).

\section{Methodology}

We model the equity returns of the banks in the sample taking into account for the property of volatility clustering. In particular, an $\mathrm{AR}(1)-\mathrm{GARCH}(1,1)$ approach is used for modelling the returns of banking sector $\mathrm{s}$ and the generic bank i at time t. Analytically:

$$
\begin{aligned}
X_{j, t} & =\mu_{j, t}+\sigma_{j, t} Z_{j, t}=\gamma X_{j, t-1}+\sigma_{j, t} \quad \text { with } \mathrm{j}=\mathrm{i}, \mathrm{s} \\
\sigma_{j, t}^{2} & =\omega_{0}+\omega_{1}\left(X_{j, t-1}-\mu_{j, t-1}\right)^{2}+\omega_{2} \sigma_{j, t-1}^{2}
\end{aligned}
$$

with $\omega_{0}, \omega_{1}, \omega_{2}>0, \omega_{1}+\omega_{2}<1$ and $|\gamma|<1, \mathrm{j}=\mathrm{i}, \mathrm{s}$. The distribution of the residuals $Z_{\mathrm{j}, \mathrm{t}}$ is modelled as a stochastic process with zero mean, variance equal to one and c.d.f. $F_{Z j, t}$.

In order to determine the CoVaR of equity returns, we can compute the CoVaR of the residuals $\operatorname{CoVaR}_{\alpha, \beta, t}^{Z}$ and then rescale it as follows:

$$
\operatorname{CoVaR}_{\alpha, \beta, t}=\mu_{s, t}+\sigma_{s, t} \operatorname{CoVaR} \alpha_{\alpha, \beta, t}^{Z}
$$


It is assumed that $\alpha=\beta=1 \%$.

$\mathrm{CoVaR}$ (and $\triangle \mathrm{CoVaR}$ ) is measured by an original approach (Di Clemente, 2018) founded on EVT for describing the margins and on Student's t copula function for representing the dependence between the banking sector and each bank. The parameters of both copula and margins (for each couple system-bank) are calibrated by means of Inference Functions for Margins (IFM) method as illustrated in Di Clemente (2018) (Note 1).

We assume that the marginal distributions of the standardized log-returns $Z_{\mathrm{i}, \mathrm{t}}$ for financial institutions are the following (Note 2):

$$
F_{i}(x)= \begin{cases}\left(1-\frac{T_{u_{i}}^{L}}{T}\right)\left(1-\xi_{i}^{L} \frac{x-u_{i}^{L}}{\beta_{i}^{L}}\right)^{-1 / \xi_{i}^{L}} & \left(x<u_{i}^{L}\right) \\ N(x ; \mu, \sigma) & \left(u_{i}^{L} \leq x<u_{i}^{R}\right) \quad, \quad \mathrm{i}=1, \ldots, \mathrm{N} \\ 1-\frac{T_{u_{i}}^{R}}{T}\left(1+\xi_{i}^{R} \frac{x-u_{i}^{R}}{\beta_{i}^{R}}\right)^{-1 / \xi_{i}^{R}} & \left(x \geq u_{i}^{R}\right)\end{cases}
$$

where $\mathrm{N}(\mathrm{x} ; \mu, \sigma)$ is the Gaussian c.d.f., $\mu$ is the mean of the random variable $\mathrm{X}$ and $\sigma$ is the standard deviation of the random variable $\mathrm{X}$.

We have selected the threshold $u_{i}^{R}$ as the highest $\mathrm{x}$ such that the normal c.d.f. $N(x ; \mu, \sigma)<1-\frac{T_{x}^{R}}{T}$, where $T_{x}^{R}$ is the number of historical returns exceeding $\mathrm{x}$. The threshold $u_{i}^{L}$ has been selected as the lowest $\mathrm{x}$ such that the normal c.d.f. $N(x ; \mu, \sigma)>\left(1-\frac{T_{x}^{L}}{T}\right)$, where $T_{x}^{L}$ is the number of returns exceeding x. In this way the monotonicity property of the c.d.f. (11) is preserved.

The copula of the bivariate Student's $t$ distribution is the Student's t copula. Let $\mathbf{X}$ be a vector with a two-variate Student's t distribution with $v$ degrees of freedom, mean vector $\boldsymbol{\mu}$ (for $v>1$ ) and covariance matrix $\frac{v}{v-2} \Sigma$ (for $v>2$ ) (Note 3). It can be represented in the following way:

$$
\mathbf{X}=\boldsymbol{d}+\frac{\sqrt{v}}{\sqrt{S}} \mathbf{Z}
$$

where $\boldsymbol{\mu} \in R^{2}, \mathrm{~S} \sim \chi_{v}^{2}$ and the random vector $\mathbf{Z} \sim N_{2}(\mathbf{0}, \Sigma)$ are independent.

The copula of vector $\mathbf{X}$ is the Student's t copula with $v$ degrees of freedom. It can be represented as follows:

$$
C_{v, R}^{t}\left(u_{1}, u_{2}\right)=t_{v, R}^{2}\left(t_{v}^{-1}\left(u_{1}\right), t_{v}^{-1}\left(u_{2}\right)\right)
$$

In equation (13) $R_{12}=\sigma_{12} / \sqrt{\sigma_{1} \sigma_{2}}$ and $t_{v, R}^{2}$ denotes the bivariate c.d.f. of the random vector $\sqrt{v} \mathbf{Y} / \sqrt{S}$, where the random variable $\mathrm{S} \sim \chi_{v}^{2}$ and the random vector $\mathbf{Y}$ (Note 4) are independent; $t_{v}$ denotes the margins (Note 5) of $t_{v, R}^{2}$. Expression (13) can be written as follows: 


$$
C_{v, R}^{t}(u, v)=\int_{-\infty}^{t_{v}^{-1}(u)} \int_{-\infty}^{t_{v}^{-1}(v)} \frac{1}{2 \pi\left(1-R_{12}^{2}\right)^{1 / 2}}\left\{1+\frac{s^{2}-2 R_{12} s t+t^{2}}{v\left(1-R_{12}^{2}\right)}\right\}^{-(v+2) / 2} d s d t
$$

where $\mathrm{R}_{12}$ is the linear correlation coefficient of the bivariate Student's $\mathrm{t}$ distribution with $v$ degrees of freedom, if $v>2$.

In our study, the STOXX Europe 600 Banks Index represents the European banking sector. Our data set is composed by the daily returns of the STOXX Europe 600 Banks Index and of every bank in the sample (25 banks) (Note 6) included in the European Banking Index from January 1, 2004 to January 8, 2015. This time span includes the latest financial crisis represented in this work by the period from July 2, 2007 to May 15, 2009.

Figure 1 represents the left tail of the cumulative distribution function (c.d.f.) of the standardized log-returns $Z_{\mathrm{s}, \mathrm{t}}$ for the banking Index with refer to three different assumptions: empirical c.d.f.; EVT c.d.f.; Standard Normal c.d.f. It is clear as Extreme Value Theory fits empirical distribution much better than the standard normal distribution.

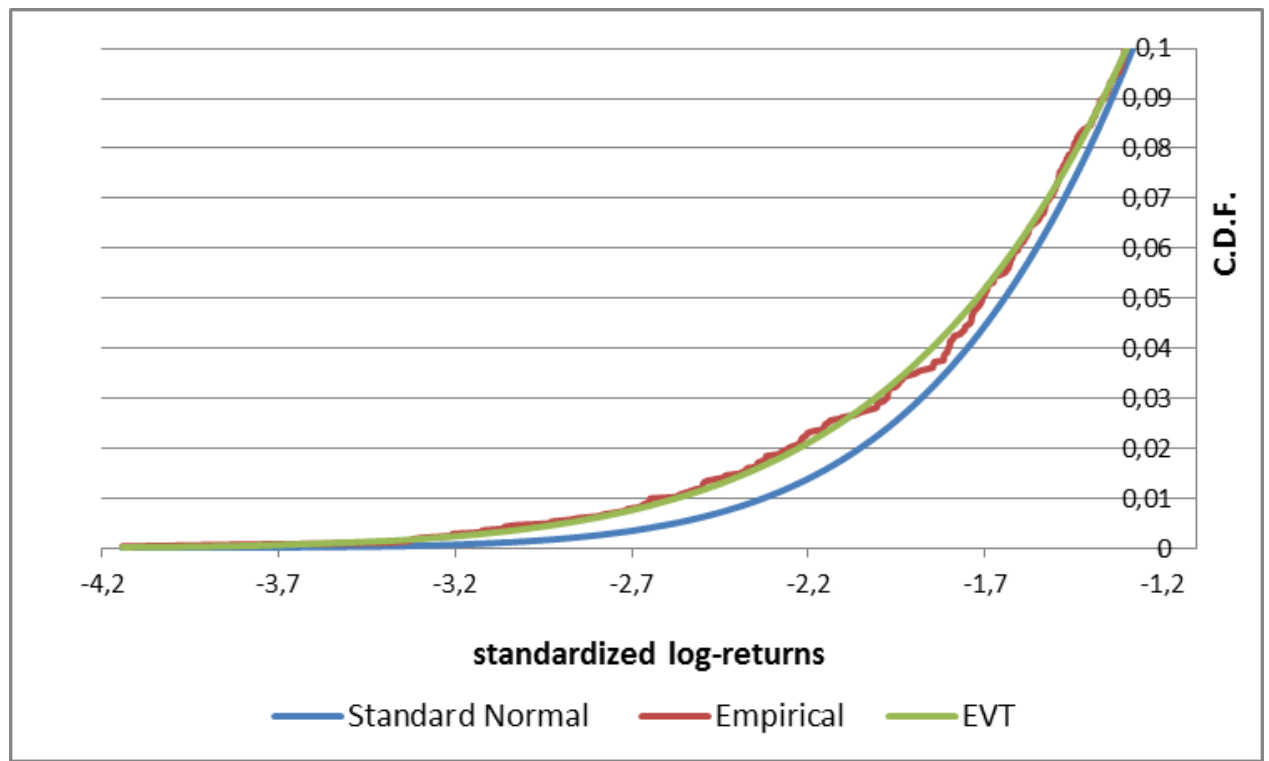

Figure 1. Left tail of the standardized $\log$-returns $Z_{\mathrm{s}, \mathrm{t}}$ of the STOXX Europe 600 Banks Index: empirical, EVT and Standard Normal assumptions

Assuming that the copula of $X_{i, t}$ and $X_{s, t}$ is the bivariate Student's t copula, Hakwa et al. (2015) demonstrated that:

$$
\operatorname{CoVaR}_{\alpha, \beta, \mathrm{t}}=\mathrm{F}_{\mathrm{s}, \mathrm{t}}^{-1}\left(\mathrm{t}_{v}\left(\rho \mathrm{t}_{v}^{-1}(\alpha)+\sqrt{\left(1-\rho^{2}\right)(v+1)^{-1}\left(v+\left[\mathrm{t}_{v}^{-1}(\alpha)\right]^{2}\right)} \mathrm{t}_{v+1}^{-1}(\beta)\right)\right)
$$

Supposing that $\mathrm{X}_{\mathrm{i}, \mathrm{t}}$ and $\mathrm{X}_{\mathrm{s}, \mathrm{t}}$ are EVT distributed as in equation (11), the following equation is obtained with refer to the left tail of the return distribution:

$$
\left.\operatorname{CoVaR}_{\alpha, \beta, t}=u_{s}^{L} \frac{\beta_{s}^{L}}{\xi_{s}^{L}}\left(1-\left(\left(t v\left(\rho t_{v}^{-1}(\alpha)+\sqrt{\left(1-\rho^{2}\right)(v+1)^{-1}\left(v+\left[t_{v}^{-1}(\alpha)\right]^{2}\right.}\right) t_{v_{+1}^{-1}}(\beta)\right)\right)^{N-N_{u s}^{L}}\right)^{-\xi_{s}^{L}}\right)
$$




$$
\text { if } t_{v}\left(\rho t_{v}^{-1}(\alpha)+\sqrt{\left(1-\rho^{2}\right)(v+1)^{-1}\left(v+\left[t_{v}^{-1}(\alpha)\right]^{2}\right)} t_{v+1}^{-1}(\beta)\right)<1-\frac{N_{u s}^{L}}{N}
$$

In our empirical study for estimating the other risk measures, MES and CES, we utilize Monte Carlo simulation for obtaining a high number of scenarios for the $\mathrm{N}$ standardized $\log$-returns $Z_{\mathrm{i}, \mathrm{t}}$ for financial institutions. The margins of the standardized log-returns $\mathrm{Z}_{\mathrm{i}, \mathrm{f}}$ for financial institutions are EVT distributed following equation (11).

For modelling the dependence structure we use the multivariate Student's t-copula that is the copula of the multivariate Student's t-distribution. Let $\mathbf{X}$ be a vector with an N-variate standardized Student's t-distribution with $v$ degrees of freedom, and covariance matrix $\frac{v}{v-2} \mathrm{R}$ (for $v>2$ ) (Note 7). It can be represented in the following way:

$$
\mathbf{X}=\frac{\sqrt{v}}{\sqrt{S}} \mathbf{Y}
$$

where, $\mathrm{S}$ is a r.v. distributed as a chi-squared with $v$ degrees of freedom $\left(\mathrm{S} \sim \chi_{v}^{2}\right)$ and $\mathbf{Y}$ is a random vector distributed as a standardized N-variate Normal $\left(\mathbf{Y} \sim N_{n}(\mathbf{0}, \mathbf{R})\right)$. S and $\mathbf{Y}$ are independent.

The copula of the vector $\mathbf{X}$ is the Student's t-copula with $v$ degrees of freedom. It can be analytically represented in the following way:

$$
C_{v, R}^{t}(u)=t_{v, R}^{n}\left(t_{v}^{-1}\left(u_{1}\right), \ldots, t_{v}^{-1}\left(u_{n}\right)\right)
$$

where $t_{v, \mathbf{R}}^{n}$ denotes the multivariate c.d.f. of the random vector $\sqrt{v} \mathbf{Y} / \sqrt{S}$, where the random variable S $\chi_{v}^{2}$ and the random vector $\mathbf{Y}$ (Note 7) are independent. $t_{v}$ denotes the margins (Note 8) of $t_{v, \mathbf{R}}^{n}$.

In order to simulate random variates from the Student's t-copula (18), $C_{v, \mathbf{R}}^{t}$, we can use the following algorithm, which is based on equation (17):

- find the Cholesky decomposition, $\mathbf{A}$, of $\mathbf{R}$;

- $\quad$ simulate $\mathrm{n}$ independent random variates $\mathbf{z}=\left(\mathrm{z}_{1}, \ldots, \mathrm{Z}_{\mathrm{n}}\right)^{\mathrm{T}}$ from the standard normal distribution $\mathrm{N}(0,1)$;

- simulate a random variate, $\mathrm{s}$, from $\chi_{v}^{2}$ distribution, independent of $\mathbf{z}$;

- determine the vector $\mathbf{y}=\mathbf{A z}$;

- set $\mathbf{x}=\frac{\sqrt{v}}{\sqrt{s}} \mathbf{y}$

- determine the components $u_{i}=t_{v}\left(x_{i}\right), i=1, \ldots, n$; the resultant vector is: $\left(u_{1}, \ldots, u_{n}\right)^{\mathrm{T}} \sim C_{v, R}^{t}$.

In this work, in order to obtain a Monte Carlo scenario $\mathbf{x}$ for the $\mathrm{N}$ financial institutions daily log-returns $\mathbf{X}$, we transform $\left(\mathrm{u}_{1}, \ldots, \mathrm{u}_{\mathrm{n}}\right)^{\mathrm{T}} \sim C_{v, \mathbf{R}}^{t}$ using the marginal distributions in equation (11). We first obtain the standardized 
asset log-returns (Note 9): $\mathbf{z}=\left(z_{1}, \ldots, z_{n}\right)^{T}=\left(F_{1}^{-1}\left(u_{1}\right), \ldots, F_{n}^{-1}\left(u_{n}\right)\right)^{T}$. Then we rescale these standardized log-returns using the square roots of the variances in equation (9): $\mathbf{x}=\left(\mathrm{x}_{1}, \ldots, \mathrm{x}_{\mathrm{n}}\right)^{\mathrm{T}}=\left(z_{1} \sigma_{1, t+1}, \ldots, z_{n} \sigma_{n, t+1}\right)^{T}$.

Given 10,000 scenarios for the $\mathrm{N}$ financial institutions daily log-returns $\mathrm{X}$, we calculate the financial system return by equation (5) in 3.2. section and $\mathrm{MES}_{\mathrm{it}}$ and $\mathrm{CES}_{\mathrm{it}}$ as in equations (7) and (8) respectively in which $\mathrm{C}$ is equal to the Value-at-Risk of the random variable $\mathrm{X}_{\mathrm{st}}$ at the probability level of $1 \%$ over a daily holding period.

\section{Empirical Analysis and Data Set}

The principal aim of this research is to evaluate the contribution of each bank in the sample to the instability of the whole European banking sector. In order to achieve this purpose, we use publicly available daily returns and employ three different systemic risk metrics (alternatively).

In particular, for each bank in the sample, we calculate daily $\triangle \mathrm{CoVaR}$, MES and CES, over a one-day holding period, with refer to the following four different time spans:

1) the mean of daily $\triangle$ CoVaRs, MESs and CESs, over the total time horizon for every bank in the sample (see Table 1);

2) the mean of daily $\triangle$ CoVaRs, MESs and CESs on the crisis period (from July 2, 2007 to May 15, 2009) for every bank (see Table 5); in this time span, the values of the STOXX Europe 600 Banks Index fell considerably (see Figure 2);

3) the daily $\triangle \mathrm{CoVaR}$, MES and CES (for each of 25 banks in the sample) in the worst day, 30th October 2008, (see Table 9), that is when the Banking Index showed its worst daily value (see Figure 2).

4) the mean of daily $\triangle$ CoVaRs, MESs and CESs on the period before the crisis (from January 1, 2004 to June 30, 2007) for each bank (see Table 13).

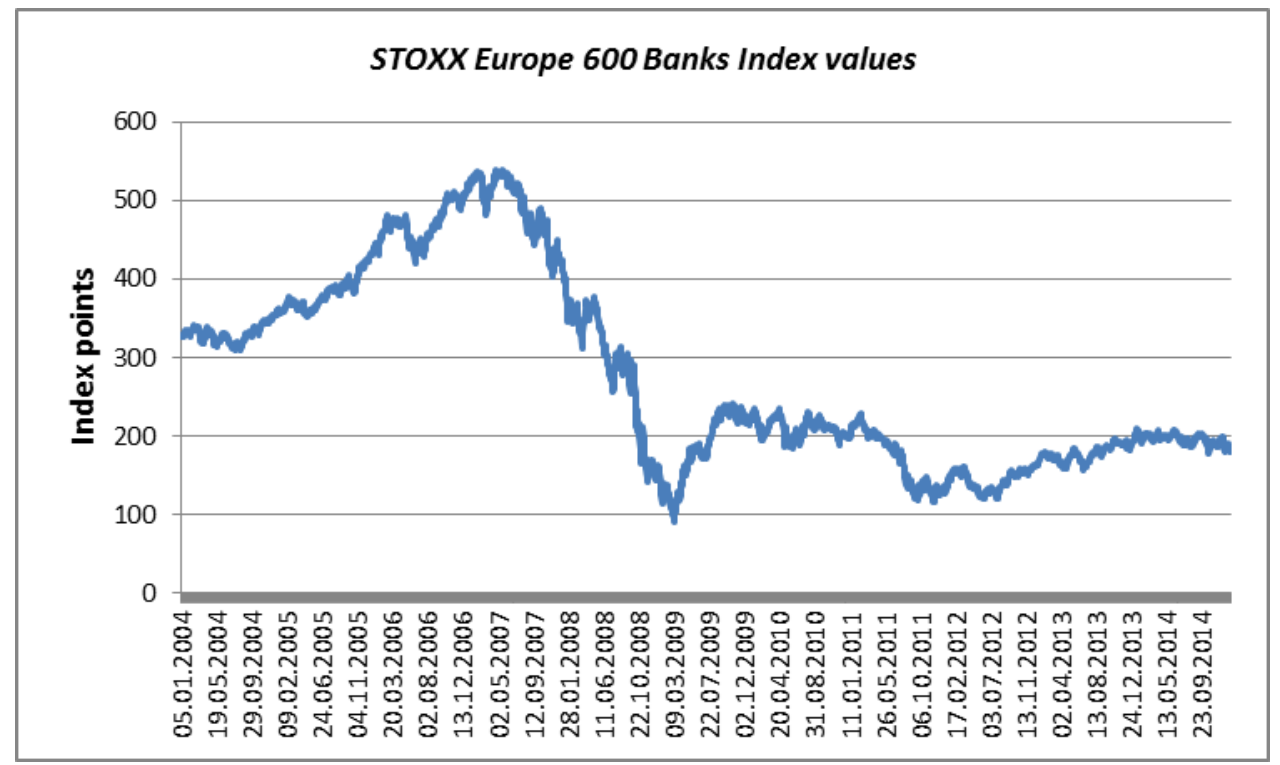

Figure 2. Time series of the values for the STOXX Europe 600 Banks Index over the total time span (from January 1, 2004 to January 8, 2015)

Note. Our elaboration by publicly available market data.

Successively, we compare the empirical results in terms of systemic risk rankings for the sample of 25 European banks (Note 10) composing the European Banking Index from January 1, 2004 to January 8, 2015.

In Tables 1, 5, 9 and 13 we collect the outcomes in terms of contribution of each institution to European systemic risk by ranking the banks according to the values of MES, CES and $\triangle \mathrm{CoVaR}$ on the four different time horizons respectively. It is interesting to analyze whether different systemic risk metrics recognize the same institutions as the most riskiness.

In addition, for each bank in the sample, we also report the risk rankings calculated by using the traditional risk 
measures of beta, rho (correlation) and market VaR of each institution.

Another aim of this research is to attest the possible existence of a strong linkage between systemic risk measures and traditional risk measures.

In Tables 2, 3 and 4 we report the numbers of concordances between pairs of different risk measures for the top 10 financial institutions, for the top 5 institutions and for the top 3 banks respectively, with refer to the total sample time period; in Tables 6, 7 and 8 the numbers of concordances between pairs of risk measures are calculated for the top 10, the top 5 and the top 3 banks on the crisis period; in Tables 10, 11 and 12 we collect the numbers of concordances between pairs of different risk metrics accounted on a particular day, that is the worst day; in Tables 14, 15 and 16 the numbers of concordances refer to the period before the crisis.

Table 1. Systemic Risk Rankings for the 25 European banks of the sample based on MES, CES and Delta CoVaR metrics and Market Risk Rankings based on Rho, Beta and VaR (total time period)

\begin{tabular}{|c|c|c|c|c|c|c|}
\hline Ranking & MES & CES & Delta CoVaR & rho & Beta & VaR \\
\hline 1 & National Bank of Greece - GR & HSBC - UK & BNP Paribas - FR & BNP Paribas - FR & Societè Generale - FR & Bank of Ireland - IR \\
\hline 2 & Societè Generale - FR & Santander - ES & Societè Generale - FR & Societè Generale - FR & Credit Agricole - FR & Eurobank Ergasias - GR \\
\hline 3 & Royal Bank of Scotland - UK & BNP Paribas - FR & Credit Agricole - FR & Deutsche Bank - DE & UniCredit - IT & National Bank of Greece - GR \\
\hline 4 & Credit Agricole - FR & Barklays - UK & Deutsche Bank - DE & Credit Agricole - FR & BNP Paribas - FR & UniCredit - IT \\
\hline 5 & Commerzbank - DE & Bilbao - ES & Intesa SanPaolo - IT & Intesa SanPaolo - IT & Commerzbank - DE & Alpha Bank - GR \\
\hline 6 & BNP Paribas - FR & Societè Generale - FR & HSBC - UK & HSBC - UK & Royal Bank of Scotland - UK & Royal Bank of Scotland - UK \\
\hline 7 & Erste Group Bank - AT & UniCredit - IT & Lloyds - UK & Lloyds - UK & Intesa SanPaolo - IT & Barklays - UK \\
\hline 8 & Barklays - UK & Deutsche Bank - DE & Commerzbank - DE & Royal Bank of Scotland - UK & BPM - IT & Erste Group Bank - AT \\
\hline 9 & Deutsche Bank - DE & Credit Suisse - $\mathrm{CH}$ & Royal Bank of Scotland - UK & Commerzbank - DE & Erste Group Bank - AT & Natixis - FR \\
\hline 10 & Eurobank Ergasias - GR & Royal Bank of Scotland - UK & UniCredit - IT & UniCredit - IT & Deutsche Bank - DE & Commerzbank - DE \\
\hline 11 & UniCredit - IT & Intesa SanPaolo - IT & Erste Group Bank - AT & Barklays - UK & Lloyds - UK & Lloyds - UK \\
\hline 12 & Alpha Bank - GR & Lloyds - UK & Natixis - FR & Erste Group Bank - AT & Barklays - UK & BPM - IT \\
\hline 13 & Intesa SanPaolo - IT & Credit Agricole - FR & MPS - IT & Natixis - FR & Natixis - FR & Societè Generale - FR \\
\hline 14 & Natixis - FR & Commerzbank - DE & Barklays - UK & Bilbao - ES & MPS - IT & Credit Agricole - FR \\
\hline 15 & MPS - IT & National Bank of Greece - GR & DNB - NO & MPS - IT & Bank of Ireland - IR & Banco Popular Espanol - ES \\
\hline 16 & Santander - ES & Danske Bank - DK & BPM - IT & Santander - ES & National Bank of Greece - GR & Danske Bank - DK \\
\hline 17 & Bilbao - ES & Erste Group Bank - AT & Santander - ES & BPM - IT & Bilbao - ES & Bilbao - ES \\
\hline 18 & BPM - IT & Bank of Ireland - IR & Bilbao - ES & Credit Suisse - CH & Santander - ES & Santander - ES \\
\hline 19 & Lloyds - UK & Alpha Bank - GR & Credit Suisse - $\mathrm{CH}$ & Danske Bank - DK & Alpha Bank - GR & DNB - NO \\
\hline 20 & Credit Suisse - $\mathrm{CH}$ & DNB - NO & Danske Bank - DK & DNB - NO & Credit Suisse - $\mathrm{CH}$ & Deutsche Bank - DE \\
\hline 21 & Bank of Ireland - IR & MPS - IT & National Bank of Greece - GR & National Bank of Greece - GR & Eurobank Ergasias - GR & Credit Suisse - $\mathrm{CH}$ \\
\hline 22 & Danske Bank - DK & Eurobank Ergasias - GR & Alpha Bank - GR & Alpha Bank - GR & DNB - NO & MPS - IT \\
\hline 23 & DNB - NO & BPM - IT & Eurobank Ergasias - GR & Bank of Ireland - IR & HSBC - UK & Intesa SanPaolo - IT \\
\hline 24 & HSBC - UK & Banco Popular Espanol - ES & Bank of Ireland - IR & Eurobank Ergasias - GR & Danske Bank - DK & BNP Paribas - FR \\
\hline 25 & Banco Popular Espanol - ES & Natixis - FR & Banco Popular Espanol - ES & Banco Popular Espanol - ES & Banco Popular Espanol - ES & HSBC - UK \\
\hline
\end{tabular}

Note. the column labelled MES displays the ranking of the 25 European banks in the sample (ranked from most to least risky) based on MES metric; the systemic risk ranking is obtained by calculating the mean value of daily MESs on the whole time horizon (from 1st January 2004 to 8th January 2015) for every institution in the sample. The following two columns display the systemic risk rankings for the same 25 financial institutions based on CES and $\triangle \mathrm{CoVaR}$ metrics respectively, obtained by calculating the mean values of daily CESs and $\Delta$ CoVaRs on the whole time period. The fourth, fifth and sixth columns show the mean values of rho, beta and VaR for every institution in the sample and on the same time period.

Table 2. Number of concordances between pairs of risk measures for the top 10 financial institutions (whole time period)

\begin{tabular}{l|cccccc|} 
Concordances & MES & CES & DeltaCoVaR & Beta & Rho & VaR \\
\hline MES & - & 5 & 6 & $\mathbf{7}$ & 4 & $\mathbf{6}$ \\
CES & 5 & - & 6 & 5 & 5 & 3 \\
DeltaCovaR & 6 & $\mathbf{6}$ & - & 6 & $\mathbf{1 0}$ & 3 \\
Beta & $\mathbf{7}$ & 5 & 6 & - & 8 & 4 \\
Rho & 4 & 5 & $\mathbf{1 0}$ & 8 & - & 3 \\
VaR & 6 & 3 & 3 & 4 & 3 & - \\
\hline
\end{tabular}

Table 3. Number of concordances between pairs of risk measures for the top 5 financial institutions (whole time period)

\begin{tabular}{l|cccccc|} 
Concordances & MES & CES & DeltaCoVaR & Beta & Rho & VaR \\
MES & - & 0 & 2 & 3 & 2 & $\mathbf{1}$ \\
CES & 0 & - & 1 & 1 & 1 & 0 \\
DeltaCovaR & 2 & 1 & - & 3 & $\mathbf{5}$ & 0 \\
Beta & $\mathbf{3}$ & 1 & 3 & - & 3 & 1 \\
Rho & 2 & 1 & $\mathbf{5}$ & 3 & - & 0 \\
VaR & 1 & 0 & 0 & 1 & 0 & - \\
\hline
\end{tabular}


Table 4. Number of concordances between pairs of risk measures for the top 3 financial institutions (whole time period)

\begin{tabular}{l|cccccc|} 
Concordances & MES & CES & DeltaCoVaR & Beta & Rho & VaR \\
\hline MES & - & 0 & 1 & 1 & 1 & $\mathbf{1}$ \\
CES & 0 & - & 1 & 0 & 0 & 0 \\
DeltaCovaR & 1 & 1 & - & 2 & 2 & 0 \\
Beta & 1 & 0 & 2 & - & 1 & 0 \\
Rho & 1 & 1 & 2 & 1 & - & 0 \\
VaR & 1 & 0 & 0 & 0 & 0 & - \\
\hline
\end{tabular}

With refer to the total sample period (see Table 1), we find a good coherence of ranking results among the three different systemic risk measures. In fact, CES and $\triangle \mathrm{CoVaR}$ identify as risky the same six banks among the top 10 most dangerous institutions; also MES and $\triangle \mathrm{CoVaR}$ detect the same six institutions, while CES and MES recognize the same five institutions as risky.

Considering the numbers of concordances between the two different type of measures (systemic and market) taken in pairs, we note as $\triangle \mathrm{CoVaR}$ and rho identify the same ten institutions. Moreover MES and beta classify the same seven institutions as risky, while MES and VaR order the same six institutions (see Table 2).

When we restrict the analysis to the top 5 most riskiness banks (see Table 3), we again find a strong coherence between the rankings calculated by $\triangle \mathrm{CoVaR}$ and by rho ( 5 concordances out of 5 banks) and an interesting consistency between the rankings based on MES and on beta (3 concordances out of 5 institutions).

If we limit the observations to the top 3 risky institutions (see Table 4), we find in particular that $\Delta \mathrm{CoVaR}$ confirms the strong linkage with rho.

From this first empirical analysis, we may affirm that the risk information captured by the correlation between each institution and the whole banking system is mostly replicated by $\triangle \mathrm{CoVaR}$ metric, while the risk information expressed by beta is gathered regularly by MES.

The CES metric appears the systemic risk measure more independent of the traditional market risk metrics of beta, VaR and rho showing a constant linkage with $\triangle \mathrm{CoVaR}$ metric.

Moreover, we observe that the top 3 risky institutions identified by CES (HSBC, Santander and BNP Paribas) are on average the most capitalized institutions on the whole sample period. Therefore we may affirm that CES emphasizes the role of firm size in the systemic risk ranking.

Differently, MES identifies National Bank of Greece as the first most risky institution perhaps due to its drawback of not taking into account the relative weight of each institution in the banking system. Moreover, we observe as National Bank of Greece shows a high value of VaR (looking at the ranking based on the VaR metric, National Bank of Greece is the third most risky bank).

Comparing the empirical results for CES with the FSB's list of G-SIBs as of November 2015 composed by using end-2014 proprietary data (see Table A), we find HSBC and BNP Paribas allocated in the most risky buckets $\left(4^{\circ}\right.$ and $3^{\circ}$ levels respectively), and Santander assigned to $1^{\circ}$ bucket (the lowest systemic risk bucket). 
Table A. List of European G-SIBs as of November 2015 identified by Financial Stability Board using end-2014 data

\begin{tabular}{cc}
\hline $\begin{array}{c}\text { Systemic Risk Bucket } \\
\text { (in decreasing order) }\end{array}$ & $\begin{array}{c}\text { European Systemically Important Banks of FSB's list } \\
\text { (in alphabetical order within each bucket) } \\
\text { (November 2015) }\end{array}$ \\
\hline 5 & HSBC (UK) \\
$(3.5 \%)$ & Barclays (UK) \\
\hline 4 & BNP Paribas (FR) \\
\hline $3 \%)$ & Deutsche Bank (DE) \\
\hline$(2.0 \%)$ & Credit Suisse (CH) \\
\hline 2 & Groupe BPCE (FR) \\
$(1.5 \%)$ & Groupe Crédit Agricole (FR) \\
ING Bank (NL) \\
Nordea (DK) \\
\\
\hline $1.0 \%)$ & Royal Bank of Scotland (UK) \\
Santander (ES) & Société Générale (FR) \\
& Standard Chartered (UK) \\
& UBS (CH) \\
& UniCredit Group (IT) \\
\hline
\end{tabular}

Note. The G-SIBs are allocated to buckets corresponding to required levels of additional capital buffers according to the greater systemic risk level. The numbers in parentheses are the required level of additional common equity loss absorbency as a percentage of risk-weighted assets that applies to each G-SIB.

When we extend the comparison with the FSB's list to the top 10 institutions identified by CES, we find a very strong coherence between the two rankings (9 concordances out of 10) with the only exception of Bilbao that does not appear on the FSB's list. We highlight that Bilbao is identified like dangerous by CES due to its high relative market capitalization.

Similarly the number of concordances between the rankings of $\triangle \mathrm{CoVaR}$ and of FSB's list is very good (8 institutions out of 10) with the exception of Intesa San Paolo and Commerzbank which do not appear on the FSB's list. $\triangle \mathrm{CoVaR}$ identifies Intesa San Paolo and Commerzbank as dangerous institutions due to their high values of correlation with European banking system.

The level of coherence with the FSB's list reduces for MES that identifies National Bank of Greece, Commerzbank, Erste Group Bank and Eurobank Ergasias as SIBs, while these banks do not appear on the FSB's list. Moreover, we note as National Bank of Greece, Commerzbank, Erste Group Bank and Eurobank Ergasias are identified as risky institutions by the VaR metric that quantifies the market tail risk of each bank in isolation.

Otherwise, we know that a bank can appear very risky when viewed alone, but it does not contribute considerably to the instability of the whole financial system mostly considering its low relative weight in the system. This is the case, in particular, for National Bank of Greece, Eurobank Ergasias and Erste Group Bank. 
Table 5. Systemic Risk Rankings for the 25 European banks of the sample based on MES, CES and Delta CoVaR metrics and Market Risk Rankings based on Rho, Beta and VaR (crisis period: from 2nd July 2007 to 15th May 2009)

\begin{tabular}{|c|c|c|c|c|c|c|}
\hline Ranking & MES & CES & Delta CoVaR & rho & Beta & VaR \\
\hline 1 & Royal Bank of Scotland - UK & HSBC - UK & BNP Paribas - FR & BNP Paribas - FR & Royal Bank of Scotland - UK & Royal Bank of Scotland - UK \\
\hline 2 & Barklays - UK & Santander - ES & Credit Agricole - FR & Credit Agricole - FR & Lloyds - UK & Bank of Ireland - IR \\
\hline 3 & Societè Generale - FR & BNP Paribas - FR & Deutsche Bank - DE & Societè Generale - FR & Natixis - FR & Barklays - UK \\
\hline 4 & BNP Paribas - FR & Credit Suisse - $\mathrm{CH}$ & HSBC - UK & Deutsche Bank - DE & Barklays - UK & UniCredit - IT \\
\hline 5 & Commerzbank - DE & Societè Generale - FR & Societè Generale - FR & Lloyds - UK & Credit Agricole - FR & Danske Bank - DK \\
\hline 6 & Credit Agricole - FR & Barklays - UK & Intesa SanPaolo - IT & HSBC - UK & Commerzbank - DE & Natixis - FR \\
\hline 7 & Natixis - FR & Bilbao - ES & Commerzbank - DE & Royal Bank of Scotland - UK & Societè Generale - FR & Lloyds - UK \\
\hline 8 & Deutsche Bank - DE & Deutsche Bank - DE & Lloyds - UK & Intesa SanPaolo - IT & BNP Paribas - FR & Commerzbank - DE \\
\hline 9 & Erste Group Bank - AT & Intesa SanPaolo - IT & Royal Bank of Scotland - UK & Commerzbank - DE & Erste Group Bank - AT & Erste Group Bank - AT \\
\hline 11 & UniCredit - IT & Credit Agricole - FR & MPS - IT & MPS - IT & Deutsche Bank - DE & Societè Generale - FR \\
\hline 12 & Danske Bank - DK & Royal Bank of Scotland - UK & Erste Group Bank - AT & Natixis - FR & Bank of Ireland - IR & DNB - NO \\
\hline 13 & Santander - ES & Lloyds - UK & Natixis - FR & DNB - NO & DNB - NO & Credit Agricole - FR \\
\hline 14 & Credit Suisse - $\mathrm{CH}$ & National Bank of Greece - GR & BPM - IT & Barklays - UK & Credit Suisse - $\mathrm{CH}$ & Santander - ES \\
\hline 15 & National Bank of Greece - GR & Commerzbank - DE & UniCredit - IT & BPM - IT & National Bank of Greece - GR & Deutsche Bank - DE \\
\hline 16 & Bilbao - ES & Danske Bank - DK & Eurobank Ergasias - GR & UniCredit - IT & Intesa SanPaolo - IT & Bilbao - ES \\
\hline 17 & Bank of Ireland - IR & Erste Group Bank - AT & Alpha Bank - GR & Bilbao - ES & HSBC - UK & Banco Popular Espanol - ES \\
\hline 18 & Intesa SanPaolo - IT & Bank of Ireland - IR & Danske Bank - DK & Danske Bank - DK & Santander - ES & Credit Suisse - CH \\
\hline 19 & HSBC - UK & Alpha Bank - GR & Barklays - UK & National Bank of Greece - GR & Bilbao - ES & Alpha Bank - GR \\
\hline 22 & BPM - IT & BPM - IT & National Bank of Greece - GR & Credit Suisse - CH & Eurobank Ergasias - GR & Intesa SanPaolo - IT \\
\hline 23 & Alpha Bank - GR & Natixis - FR & Credit Suisse - $\mathrm{CH}$ & Eurobank Ergasias - GR & Alpha Bank - GR & BNP Paribas - FR \\
\hline 24 & Eurobank Ergasias - GR & Banco Popular Espanol-ES & Banco Popular Espanol - ES & Bank of Ireland - IR & Danske Bank - DK & HSBC - UK \\
\hline 25 & Banco Popular Espanol - ES & Eurobank Ergasias - GR & Bank of Ireland - IR & Banco Popular Espanol - ES & Banco Popular Espanol - ES & BPM - IT \\
\hline
\end{tabular}

Note. The column labelled MES displays the ranking of the 25 European banks in the sample (ranked from most to least risky) based on MES metric; the systemic risk ranking is obtained by calculating the mean value of daily MESs over the crisis period (from 2nd July 2007 to 15th May 2009) for each bank in the sample. The following two columns display the systemic risk rankings for the same 25 financial institutions based on CES and $\triangle$ CoVaR metrics, respectively, obtained by calculating the mean values of daily CESs and $\Delta$ CoVaRs over the crisis period. The fourth, fifth and sixth columns show the mean values of three firm characteristics: rho, beta and VaR for each bank in the sample.

Table 6. Number of concordances between pairs of risk measures for the top 10 financial institutions (crisis period)

\begin{tabular}{l|cccccc|} 
Concordances & MES & CES & DeltaCoVaR & Beta & Rho & VaR \\
\hline MES & - & 4 & 7 & $\mathbf{9}$ & 8 & $\mathbf{6}$ \\
CES & 4 & - & $\mathbf{8}$ & 5 & 7 & 2 \\
DeltaCovaR & 7 & $\mathbf{5}$ & - & 6 & 8 & 3 \\
Beta & $\mathbf{9}$ & 4 & 6 & - & 6 & 7 \\
Rho & 8 & 4 & $\mathbf{8}$ & 6 & - & 4 \\
VaR & 6 & 2 & 3 & 7 & 4 & - \\
\hline
\end{tabular}

Table 7. Number of concordances between pairs of risk measures for the top 5 financial institutions (crisis period)

\begin{tabular}{l|cccccc|} 
Concordances & MES & CES & DeltaCoVaR & Beta & Rho & VaR \\
\hline MES & - & 2 & 2 & $\mathbf{2}$ & 2 & $\mathbf{2}$ \\
CES & 2 & - & 3 & 0 & 2 & 0 \\
DeltaCovaR & 2 & $\mathbf{3}$ & - & 1 & $\mathbf{4}$ & 0 \\
Beta & 2 & 0 & 1 & - & 2 & 2 \\
Rho & 2 & 2 & $\mathbf{4}$ & 2 & - & 0 \\
VaR & 2 & 0 & $\mathbf{0}$ & 2 & 0 & - \\
\hline
\end{tabular}

Table 8. Number of concordances between pairs of risk measures for the top 3 financial institutions (crisis period)

\begin{tabular}{l|cccccc} 
Concordances & MES & CES & DeltaCoVaR & Beta & Rho & VaR \\
\hline MES & - & 0 & 0 & $\mathbf{1}$ & 1 & $\mathbf{2}$ \\
CES & 0 & - & 1 & 0 & 0 & 0 \\
DeltaCovaR & 0 & $\mathbf{1}$ & - & 0 & $\mathbf{2}$ & 0 \\
Beta & 1 & 0 & 0 & - & 0 & 1 \\
Rho & 1 & 1 & 2 & 0 & - & 0 \\
VaR & $\mathbf{2}$ & 0 & 0 & 1 & 0 & - \\
\hline
\end{tabular}


Observing the results from the risk rankings with refer to the crisis period (from July 2, 2007 to May 15, 2009), we may affirm that the strong linkage between MES and beta is confirmed as well as the positive relationship between $\triangle \mathrm{CoVaR}$ and correlation (see Table 5).

Among the three systemic risk metrics the most number of concordances are found for CES and $\triangle \mathrm{CoVaR}$. In addition, we underline as the systemic risk metric of MES again displays a strong positive link with the regulatory risk metric of market VaR (see Tables 5, 6, 7, 8).

Always with refer to the crisis period we find for the CES metric a strong concordance with the FSB's list (see Table A). Looking at the top 10 institutions ranked by CES as systemically dangerous banks, eight institutions are identified as SIBs by FSB too, with the exception of Bilbao (ES) and Intesa SanPaolo (IT). For $\Delta$ CoVaR as well as for MES the numbers of concordances with the FSB's list reduce to six institutions.

When we focus the empirical analysis on the worst day (October 30, 2008), we may confirm the strong positive linkage between MES and beta as well as the positive relationship between $\triangle \mathrm{CoVaR}$ and the correlation between every bank and the system (see Tables $9,10,11,12$ ).

Table 9. Systemic Risk Rankings for the 25 European banks of the sample based on MES, CES and Delta CoVaR metrics and Market Risk Rankings based on Rho, Beta and VaR (worst day: $30^{\text {th }}$ October 2008)

\begin{tabular}{|c|c|c|c|c|c|c|}
\hline Ranking & MES & CES & Delta CoVaR & rho & Beta & VaR \\
\hline 1 & Royal Bank of Scotland - UK & HSBC - UK & Credit Agricole - FR & HSBC-UK & Royal Bank of Scotland - UK & Royal Bank of Scotland - UK \\
\hline 2 & Commerzbank - DE & Santander - ES & Deutsche Bank - DE & Intesa SanPaolo - IT & Commerzbank - DE & Barklays - UK \\
\hline 3 & Barklays - UK & BNP Paribas - FR & BNP Paribas - FR & Deutsche Bank - DE & Erste Group Bank - AT & Bank of Ireland - IR \\
\hline 4 & Credit Agricole - FR & Credit Suisse - $\mathrm{CH}$ & HSBC - UK & Credit Agricole - FR & Credit Agricole - FR & Commerzbank - DE \\
\hline 5 & Societè Generale - FR & Societè Generale - FR & Intesa SanPaolo - IT & BNP Paribas - FR & UniCredit - IT & UniCredit - IT \\
\hline 6 & Deutsche Bank - DE & Bilbao - ES & DNB - NO & DNB - NO & DNB - NO & National Bank of Greece - GR \\
\hline 7 & Credit Suisse - $\mathrm{CH}$ & Royal Bank of Scotland - UK & Societè Generale - FR & Societè Generale - FR & Deutsche Bank - DE & Erste Group Bank - AT \\
\hline 8 & Erste Group Bank - AT & Intesa SanPaolo - IT & Commerzbank - DE & MPS - IT & Natixis - FR & Lloyds - UK \\
\hline 9 & BNP Paribas - FR & Barklays - UK & Erste Group Bank - AT & Erste Group Bank - AT & Societè Generale - FR & DNB - NO \\
\hline 10 & Santander - ES & UniCredit - IT & MPS - IT & UniCredit - IT & Intesa SanPaolo - IT & Natixis - FR \\
\hline 11 & Intesa SanPaolo - IT & Deutsche Bank - DE & Danske Bank - DK & Danske Bank - DK & Danske Bank - DK & Credit Agricole - FR \\
\hline 12 & National Bank of Greece - GR & Credit Agricole - FR & Natixis - FR & Natixis - FR & Barklays - UK & Societè Generale - FR \\
\hline 13 & Natixis - FR & Lloyds - UK & Eurobank Ergasias - GR & Commerzbank - DE & Lloyds - UK & Deutsche Bank - DE \\
\hline 14 & Bilbao - ES & National Bank of Greece - GR & Lloyds - UK & BPM - IT & BNP Paribas - FR & Santander - ES \\
\hline 15 & Lloyds - UK & Commerzbank - DE & Banco Popular Espanol - ES & Banco Popular Espanol - ES & BPM - IT & Danske Bank - DK \\
\hline 16 & UniCredit - IT & Erste Group Bank - AT & Royal Bank of Scotland - UK & Eurobank Ergasias - GR & Bank of Ireland - IR & Bilbao - ES \\
\hline 17 & DNB - NO & Danske Bank - DK & BPM - IT & Alpha Bank - GR & HSBC - UK & BPM - IT \\
\hline 18 & BPM - IT & DNB - NO & UniCredit - IT & Royal Bank of Scotland - UK & Santander - ES & Credit Suisse - $\mathrm{CH}$ \\
\hline 19 & HSBC - UK & MPS - IT & Alpha Bank - GR & Lloyds - UK & Banco Popular Espanol - ES & MPS - IT \\
\hline 20 & Danske Bank - DK & Alpha Bank - GR & Barklays - UK & Bilbao-ES & Bilbao - ES & Banco Popular Espanol - ES \\
\hline 21 & Bank of Ireland - IR & Banco Popular Espanol - ES & Bilbao - ES & Santander - ES & Eurobank Ergasias - GR & Intesa SanPaolo - IT \\
\hline 22 & MPS - IT & Bank of Ireland - IR & Santander - ES & Barklays - UK & National Bank of Greece - GR & BNP Paribas - FR \\
\hline 23 & Alpha Bank - GR & Natixis - FR & National Bank of Greece - GR & Bank of Ireland - IR & Alpha Bank - GR & Alpha Bank - GR \\
\hline 24 & Eurobank Ergasias - GR & BPM - IT & Bank of Ireland - IR & National Bank of Greece - GR & Credit Suisse - CH & Eurobank Ergasias - GR \\
\hline 25 & Banco Popular Espanol - ES & Eurobank Ergasias - GR & Credit Suisse - $\mathrm{CH}$ & Credit Suisse - $\mathrm{CH}$ & MPS - IT & HSBC - UK \\
\hline
\end{tabular}

Table 10. Number of concordances between pairs of risk measures for the top 10 financial institutions (worst day)

\begin{tabular}{l|cccccc|} 
Concordances & MES & CES & DeltaCoVaR & Beta & Rho & VaR \\
\hline MES & - & $\mathbf{6}$ & 5 & 6 & 5 & $\mathbf{4}$ \\
CES & 6 & - & 4 & 4 & 5 & 3 \\
DeltaCovaR & 5 & 4 & - & 7 & $\mathbf{9}$ & 3 \\
Beta & 6 & 4 & 7 & - & 7 & 6 \\
Rho & 5 & 5 & $\mathbf{9}$ & 7 & - & 3 \\
VaR & 4 & 3 & 3 & 6 & 3 & - \\
\hline
\end{tabular}

Table 11. Number of concordances between pairs of risk measures for the top 5 financial institutions (worst day)

\begin{tabular}{l|cccccc} 
Concordances & MES & CES & DeltaCoVaR & Beta & Rho & VaR \\
MES & - & 1 & 1 & $\mathbf{3}$ & 1 & $\mathbf{3}$ \\
CES & 1 & - & 2 & 1 & 2 & 0 \\
DeltaCovaR & 1 & $\mathbf{2}$ & - & 1 & $\mathbf{5}$ & 0 \\
Beta & 3 & 0 & 1 & - & 1 & 3 \\
Rho & 1 & 2 & $\mathbf{5}$ & 1 & - & 0 \\
VaR & 3 & 0 & 0 & 3 & 0 & - \\
\hline
\end{tabular}


Table 12. Number of concordances between pairs of risk measures for the top 3 financial institutions (worst day)

\begin{tabular}{l|cccccc|} 
Concordances & MES & CES & DeltaCoVaR & Beta & Rho & VaR \\
\hline MES & - & 0 & 0 & $\mathbf{2}$ & 0 & $\mathbf{2}$ \\
CES & 0 & - & 1 & 0 & 1 & 0 \\
DeltaCovaR & 0 & $\mathbf{1}$ & - & 0 & 1 & 0 \\
Beta & 2 & 0 & 0 & - & 0 & 1 \\
Rho & 0 & 1 & 1 & 0 & - & 0 \\
VaR & 2 & 0 & 0 & 1 & 0 & - \\
\hline
\end{tabular}

Looking at the top 10 risky institutions, we find for CES metric a high number of concordances with the FSB's list (8 institutions out of 10); only Bilbao and Intesa SanPaolo do not appear in the FSB's list. CES identifies Bilbao and Intesa SanPaolo as systemically dangerous institutions probably due to their high relative capitalization values.

Always considering the top 10 banks, also for the systemic metric of MES we verify 8 concordances out of 10 with the FSB's list, except for Commerzbank and Erste Group Bank which are not identified as SIBs by Financial Stability Board. Commerzbank and Erste Group Bank show high values of beta and VaR respectively on the worst day.

For the top 10 risky institutions ranked by $\triangle \mathrm{CoVaR}$, the number of concordances with FSB's list drops to five; in fact, $\triangle$ CoVaR identifies Intesa SanPaolo, DNB, Commerzbank, MPS, and Erste Group Bank as dangerous institutions differently from the FSB's list. It is interesting to observe as Intesa SanPaolo, DNB, MPS, and Erste Group Bank show high correlation values, while Commerzbank shows an high beta value together with Erste Group Bank, DNB, and Intesa SanPaolo. Commerzbank, Erste Group Bank and DNB show high values of VaR too (see Table 9).

When we restrict the comparison with the FSB's list to the top 5 risky institutions, the CES metric improves its performance identifying five institutions out of five.

Differently MES identifies Commerzbank like SIB, while this bank does not appear on the FSB's list. Also the metric of $\triangle \mathrm{CoVaR}$ classifies Intesa SanPaolo as SIB differently from FSB.

In order to further confirm the consistency of these results, we have focused the comparative analysis among the different systemic risk measures on the period before the crisis, that is from January 1, 2004 to June 30, 2007 (pre-crisis period).

The different ranking outcomes in terms of systemic risk calculated by MES, CES and $\Delta$ CoVaR and the market risk rankings based on the traditional metrics of rho, beta and VaR are collected in Table 13 for pre-crisis period.

Table 13. Systemic Risk Rankings for the 25 European banks of the sample based on MES, CES and Delta CoVaR metrics and Market Risk Rankings based on Rho, Beta and VaR (pre-crisis period)

\begin{tabular}{|c|c|c|c|c|c|c|}
\hline Ranking & MES & CES & Delta CoVaR & Tho & Beta & VaR \\
\hline 1 & Erste Group Bank - AT & UniCredit - IT & Societè Generale - FR & Societè Generale - FR & Societè Generale - FR & UniCredit - IT \\
\hline 2 & UniCredit - IT & HSBC - UK & BNP Paribas - FR & BNP Paribas - FR & BNP Paribas - FR & Erste Group Bank - AT \\
\hline 3 & Commerzbank - DE & Royal Bank of Scotland - UK & Deutsche Bank - DE & Deutsche Bank - DE & Deutsche Bank - DE & Alpha Bank - GR \\
\hline 4 & Credit Agricole - FR & Santander - ES & Lloyds - UK & Lloyds - UK & Credit Agricole - FR & National Bank of Greece - GR \\
\hline 5 & BNP Paribas - FR & BNP Paribas - FR & Credit Agricole - FR & Credit Agricole - FR & Commerzbank - DE & Bank of Ireland - IR \\
\hline 6 & Societè Generale - FR & Barklays - UK & HSBC - UK & HSBC - UK & Erste Group Bank - AT & Eurobank Ergasias - GR \\
\hline 7 & National Bank of Greece - GR & Societè Generale - FR & Royal Bank of Scotland - UK & Royal Bank of Scotland - UK & UniCredit - IT & Commerzbank - DE \\
\hline 8 & Deutsche Bank - DE & Credit Suisse - CH & Commerzbank - DE & Commerzbank - DE & BPM - IT & Natixis - FR \\
\hline 9 & Alpha Bank - GR & Deutsche Bank - DE & Intesa SanPaolo - IT & Intesa SanPaolo - IT & Royal Bank of Scotland - UK & BPM - IT \\
\hline 11 & Santander - ES & Credit Agricole - FR & Barklays - UK & Barklays - UK & Intesa SanPaolo - IT & Royal Bank of Scotland - UK \\
\hline 12 & Royal Bank of Scotland - UK & Lloyds - UK & BPM - IT & BPM - IT & Alpha Bank - GR & Credit Agricole - FR \\
\hline 13 & Natixis - FR & Commerzbank - DE & Santander - ES & Danske Bank - DK & MPS - IT & Barklays - UK \\
\hline 14 & Barklays - UK & Intesa SanPaolo - IT & Bilbao - ES & Bilbao - ES & Barklays - UK & Santander - ES \\
\hline 15 & BPM - IT & Erste Group Bank - AT & UniCredit - IT & Santander - ES & Credit Suisse - $\mathrm{CH}$ & Societè Generale - FR \\
\hline 16 & Bilbao - ES & National Bank of Greece - GR & Danske Bank - DK & Credit Suisse - CH & Santander - ES & Bilbao - ES \\
\hline 17 & MPS - IT & Bank of Ireland - IR & Credit Suisse - CH & Erste Group Bank - AT & Bilbao - ES & Deutsche Bank - DE \\
\hline 18 & Credit Suisse - $\mathrm{CH}$ & Alpha Bank - GR & Erste Group Bank - AT & UniCredit - IT & Natixis - FR & Banco Popular Espanol - ES \\
\hline 19 & Eurobank Ergasias - GR & Danske Bank - DK & Alpha Bank - GR & Alpha Bank - GR & HSBC - UK & Danske Bank - DK \\
\hline 22 & HSBC - UK & MPS - IT & National Bank of Greece - GR & Eurobank Ergasias - GR & Danske Bank - DK & MPS - IT \\
\hline 23 & Lloyds - UK & BPM - IT & Eurobank Ergasias - GR & National Bank of Greece - GR & Eurobank Ergasias - GR & Intesa SanPaolo - IT \\
\hline 24 & Danske Bank - DK & Banco Popular Espanol - ES & Banco Popular Espanol - ES & Banco Popular Espanol - ES & Bank of Ireland - IR & HSBC - UK \\
\hline 25 & Banco Popular Espanol - ES & Natixis - FR & Bank of Ireland - IR & Bank of Ireland - IR & Banco Popular Espanol - ES & BNP Paribas - FR \\
\hline
\end{tabular}


Table 14. Number of concordances between pairs of risk measures for the top 10 financial institutions (pre-crisis period)

\begin{tabular}{l|cccccc|} 
Concordances & MES & CES & $\Delta$ CoVaR & Beta & Rho & VaR \\
\hline MES & - & 4 & 6 & 6 & 6 & $\mathbf{5}$ \\
CES & 4 & - & 5 & 5 & 5 & 1 \\
DeltaCovaR & 6 & $\mathbf{5}$ & - & 7 & $\mathbf{1 0}$ & 1 \\
Beta & 6 & 5 & 7 & - & 7 & 4 \\
Rho & 6 & 5 & $\mathbf{1 0}$ & 7 & - & 1 \\
VaR & 5 & 1 & 1 & 4 & 1 & - \\
\hline
\end{tabular}

Table 15. Number of concordances between pairs of risk measures for the top 5 financial institutions (pre-crisis period)

\begin{tabular}{l|cccccc} 
Concordances & MES & CES & DeltaCoVaR & Beta & Rho & VaR \\
\hline MES & - & 2 & 2 & 3 & 2 & 1 \\
CES & 2 & - & 1 & 1 & 1 & 1 \\
DeltaCovaR & 2 & 1 & - & 4 & $\mathbf{5}$ & 0 \\
Beta & 3 & 1 & 4 & - & 3 & 0 \\
Rho & 2 & 1 & $\mathbf{5}$ & 3 & - & 0 \\
VaR & 1 & 1 & 0 & 0 & 0 & - \\
\hline
\end{tabular}

Table 16. Number of concordances between pairs of risk measures for the top 3 financial institutions (pre-crisis period)

\begin{tabular}{l|cccccc|} 
Concordances & MES & CES & DeltaCoVaR & Beta & Rho & VaR \\
\hline MES & - & 1 & 0 & 0 & 0 & 1 \\
CES & 1 & - & 0 & 0 & 0 & 1 \\
DeltaCovaR & 0 & 0 & - & 3 & 3 & 0 \\
Beta & 0 & 0 & $\mathbf{3}$ & - & 3 & 0 \\
Rho & 0 & 0 & $\mathbf{3}$ & 3 & - & 0 \\
VaR & 1 & 1 & 0 & 0 & 0 & - \\
\hline
\end{tabular}

Observing the numbers of concordances between pairs of risk measures (collected in Tables 14, 15 and 16), we may confirm the constant strong positive linkage between $\triangle \mathrm{CoVaR}$ and rho. Differently from the previous analyses, for the pre-crisis period we also find a robust positive relationship between $\Delta \mathrm{CoVaR}$ and beta.

Comparing the systemic risk rankings based on MES, CES and $\triangle \mathrm{CoVaR}$ with the list of G-SIBs identified by FSB we find for the top 10 systemically risky banks that CES recognizes as SIBs the same nine banks identified by FSB's list, with the exception of Bilbao. The number of concordances between $\triangle$ CoVaR and FSB'list decreases to seven banks out of ten. In fact, $\Delta$ CoVaR categorizes Commerzbank (DE), Intesa SanPaolo (IT) and MPS (IT) as systemically risky banks differently from FSB's list because of their high correlation values. The number of concordances between MES and the FSB's list drops to five banks.

When we focus the comparisons on the top 5 risky banks, we find that CES confirms the very high level of concordance with FSB's list (5 banks out of 5); also $\triangle$ CoVaR shows with the FSB's list a good number of concordances equal to four banks (except for Lloyd). The number of concordances for MES drops to three banks out of five. MES identifies Erste Group Bank (AT) and Commerzbank (DE) as systemically risky banks differently from FSB.

In conclusion, also for the pre-crisis period the overall results are consistent with those achieved for the crisis period, the worst day and the whole period.

In particular, the systemic metric of CES shows a very high level of consistency with the results derived from the G-SIBs identification model adopted by FSB. The only exception is Bilbao identified like SIB by CES with refer to all four different sample time horizons (Intesa SanPaolo is categorized as SIB by CES only in relation to the crisis period and the worst day).

Additionally, CES is more independent than MES and $\triangle \mathrm{CoVaR}$ from the traditional risk measures of beta and rho. In other words, the CES metric does not replicate the risk rankings based on the traditional market risk metrics offering to regulatory authorities and to financial investors a "new" risk information regarding the financial system fragility. 


\section{Conclusion}

This work offers for European banking sector an original empirical analysis with refer to three different systemic risk measures: MES, CES and $\triangle \mathrm{CoVaR}$.

While MES and $\triangle \mathrm{CoVaR}$ are two metrics well known and recognized by financial researchers and regulatory authorities, the CES measure is more recent and less famous.

We underline as the main purpose of this research is to select the riskiest financial institutions by directly ranking the banks according to their systemic riskiness based on MES, CES and $\triangle \mathrm{CoVaR}$ metrics, respectively.

With refer to the above aim, we find a good coherence of ranking results among the three different systemic risk measures. In particular, CES and $\triangle \mathrm{CoVaR}$ show the greatest level of agreement between them in terms of systemic risk rankings.

With refer to MES, we discover a strong linkage with the traditional market risk measure of beta. We remember as beta quantifies the amount of systematic risk of an institution or, in other words, the risk not eliminable by portfolio diversification. For this reason, we argue that MES helps little to order European banks for their systemic importance.

In fact, this strong positive relationship between MES and beta can generate confusion between the concepts of systemic and systematic risk respectively. The former quantifies the contribution of each financial institution to the tail risk of the whole financial system, while the latter measures the traditional market risk of an institution, that is its sensitivity to market volatility.

Also Benoit et al. (2013) found a strong positive relationship between MES and beta for a sample of top financial US institutions over the period 2000-2010. According to Benoit et al. (2013), this result denotes that systemic risk ranking of financial institutions based on MES may reflect ranking obtained by ordering institutions on the traditional systematic (or market) risk measure of Sharpe's beta.

Moreover, MES categorizes National Bank of Greece as the first most risky institution on the whole sample time period due to its drawback of not taking into account the relative weight of each institution in the banking system (measured by its relative market capitalization). This drawback of MES has been also underlined in the study of Banulescu and Dumitrescu (2013) for US financial institutions over the period 2002-2007.

In addition, our empirical study discovers for $\triangle \mathrm{CoVaR}$ metric an interesting strong linkage with the correlation between each bank and the banking system. From these results, in our opinion, $\Delta$ CoVaR seems to reproduce better the paradigm of the too-interconnected-to-fail.

Moreover, in our study, $\triangle \mathrm{CoVaR}$ shows also a weak linkage with market $\mathrm{VaR}$, coherently with the findings of other researchers. We remember as previously Adrian and Brunnermeier $(2011 ; 2016)$ underlined as $\Delta \mathrm{CoVaR}$ is not equivalent to VaR; in particular, they reported a weak relationship between the market tail risk of an institution measured in isolation by its $\mathrm{VaR}$ and the $\triangle \mathrm{CoVaR}$ of the same institution. Also Benoit et al. (2013) found a weak linkage between the market VaR of each institution and its contribution to systemic risk, measured by its $\triangle$ CoVaR. In particular, their empirical studies on US financial sector over the period 2000-2010 confirmed as systemic risk ranking of US financial institutions based on $\triangle \mathrm{CoVaR}$ does not mirror ranking obtained by ordering institutions on market VaR.

With refer to CES, our empirical outcomes underline as this systemic metric emphasizes the role of firm's size, expressed in terms of its relative market capitalization, in determining its contribution to the distress of the whole financial system. Consequently, CES metric appears in line with the "too-big-to-fail" paradigm coherently with the empirical results of Banulescu and Dumitrescu (2013) for US financial institutions over the period 2002-2007.

In addition, we discover that CES is more independent than MES and $\triangle \mathrm{CoVaR}$ from the traditional risk measures of beta and rho. In other words, the CES metric does not replicate the risk rankings based on the traditional market risk metrics offering to regulatory authorities and to financial investors a "new" risk information concerning the financial system fragility.

Moreover, we find that CES exhibits an interesting good concordance with $\triangle \mathrm{CoVaR}$ in ranking the systemic risk contributions of each institution.

In the light of our empirical findings, we argue that CES offers an interesting compromise between the two paradigms of "too-big-to-fail" and "too-interconnected-to-fail", respectively.

Finally, among the three different systemic metrics, CES shows also the highest level of concordance with the 
list of G-SIBs identified by Financial Stability Board (November 2015) with refer to European Banking Sector. Differently from FSB's list, only Bilbao is recognized as SIB by CES with refer to all four different sample time horizons; while Intesa SanPaolo is categorized as SIB by CES only in relation to the crisis period and the worst day.

Because of all the above considerations, our final conclusion is that CES, a new a very simple metric that measures the absolute contribution of an institution to the risk of the entire financial system (as opposed to the marginal contribution), may be an interesting candidate for regulatory systemic risk metric.

\section{References}

Acharya, V. V., Engle, R. F., \& Richardson, M. (2012). Capital Shortfall: A New Approach to Ranking and Regulating Systemic Risks. American Economic Review, 102(3), 59-64. https://doi.org/10.1257/aer.102.3.59

Acharya, V. V., Pedersen, L., Philippon, T., \& Richardson, M. (2017). Measuring Systemic Risk. Review of Financial Studies, 30(1), 2-47. https://doi.org/10.1093/rfs/hhw088

Adrian, T., \& Brunnermeier, M. K. (2011). CoVaR. Staff Report, 348, Federal Reserve Bank of New York. https://doi.org/10.3386/w17454

Adrian, T., \& Brunnermeier, M. K. (2016). CoVaR. American Economic Review, 106(7), 1705-1741. https://doi.org/10.1257/aer.20120555

Banulescu, G. D., \& Dumitrescu, E. I. (2013). Which are the SIFI? A Component Expected Shortfall (CES) Approach to Systemic Risk. Journal of Banking and Finance, 50, 575-588. https://doi.org/10.1016/j.jbankfin.2014.01.037

Basel Committee on Banking Supervision. (2010). Assessing the macroeconomic impact of the transition to stronger capital and liquidity requirements. Final Report, Basel, December.

Basel Committee on Banking Supervision. (2011). Global systemically important banks: assessment methodology and the additional loss absorbency requirement. Technical Document, Bank for International Settlements, Basel, November

Basel Committee on Banking Supervision. (2013). Global systemically important banks: updated assessment methodology and the higher loss absorbency requirement. Technical Document, Bank of International Settlements, Basel, July.

Benoit, S., Colletaz G., Hulin, C., \& Pérignon, C. (2013). A Theoretical and Empirical Comparison of Systemic Risk Measures. HEC Paris Research Paper, No. FIN-2014-1030.

Brownlees, C.T., \& Engle, R.F., (2017). SRISK: a conditional capital shortfall measure of systemic risk. The Review of Financial Studies, 30, 48-79. https://doi.org/10.1093/rfs/hhw060

Brownlees, T. C., \& Engle, R. F. (2012). Volatility, Correlation and Tails for Systemic Risk Measurement. Working Paper, Stern School of Business, New York.

Di Clemente, A. (2018). Estimating the marginal contribution to systemic risk by a CoVaR-model based on copula functions and Extreme Value Theory. Economic Notes - Review of Banking, Finance and Monetary Economics, 47(1), 69-112. https://doi.org/10.1111/ecno.12095

Embrechts, P., Klüppelberg, C., \& and Mikosch, T. (1997). Modelling extremal events for insurance and finance. Berlin, Springer-Verlag. https://doi.org/10.1007/978-3-642-33483-2

Financial Stability Board. (2015). 2015 update of list of global systemically important banks (G-SIBs). Technical Report, 3 November.

Hakwa, B., Jäger-Ambrożewicz, M., \& Rüdiger, B. (2015). Analysing Systemic Risk Contribution Using a Closed Formula for Conditional Value-at-Risk through Copula. Communication on Stochastic Analysis, 9(1), 131-158. https://doi.org/10.31390/cosa.9.1.08

International Monetary Fund. (2009). Global Financial Stability Report: Responding to the Financial Crisis and Measuring Systemic Risk. Washington DC.

Jorion, P. (2007). Value at Risk: The New Benchmark for Managing Financial Risk. New York, NY: McGraw-Hill. 3rd Edition.

Karimalis, E. N., \& Nomikos, N. K. (2018). Measuring systemic risk in the European banking sector: a Copula CoVaR approach. The European Journal of Finance, 24(11), 944-975. 
https://doi.org/10.1080/1351847X.2017.1366350

McNeil, A. J., \& Frey, R. (2000). Estimation of Tail-Related Risk Measures for Heteroscedastic Financial Time Series: an Extreme Value Approach. Journal of Empirical Finance, 7(3-4), 271-300. https://doi.org/10.1016/S0927-5398(00)00012-8

Nelsen, R. (1998). An Introduction to Copulas. New York, NY: Springer.

Sharpe, W. F. (1964). Capital Asset Prices: A Theory of Market Equilibrium under Conditions of Risk. The Journal of Finance, 19(3), 425-442.

Sklar, A. (1959). Fonctions de répartition à n dimensions et leurs marges. Publications de l'Institut de Statistique de l'Université de Paris, 8, 229-231.

Sklar, A. (1996). Random variables, distribution functions, and copulas - a personal look backward and forward. In L. Rüschendorff, B. Schweizer \& M. Taylor (Eds), Distributions with Fixed Marginals and Related Topics (pp. 1-14). Hayward, CA: Institute of Mathematical Statistics. https://doi.org/10.1214//nms/1215452606

Yamai, Y., \& Yoshiba, T. (2002). Comparative analyses of Expected Shortfall and Value-at-Risk (3): their validity under market stress. Institute for Monetary and Economic Studies, 20(2), Bank of Japan, Tokyo, October, 181-238.

\section{Notes}

Note 1. For a more accurate description of the whole analytical procedure see Di Clemente (2018) section 3.3.

Note 2. They are quite similar to those used in McNeil and Frey (2000) and Yamai and Yoshiba (2002).

Note 3. If $v \leq 2$, then the covariance matrix is not defined.

Note 4. $\mathbf{Y}$ has a two-dimensional normal distribution with mean vector $\mathbf{0}$ and covariance matrix $\mathbf{R}$.

Note 5. All the margins are equally distributed.

Note 6. If $v \leq 2$, then the covariance matrix is not defined.

Note 7. Y has a n-dimensional normal distribution with mean vector $\mathbf{0}$ and covariance matrix $\mathbf{R}$.

Note 8 . All the margins are equally distributed.

Note 9. $F_{i}^{-1}$ is the generalized inverse of the c.d.f. (14).

Note 10. We selected 25 European banks among the 49 banks included in European Banking Index (March, 2015) because of the equity returns availability for the analysed entire time horizon.

\section{Copyrights}

Copyright for this article is retained by the author(s), with first publication rights granted to the journal.

This is an open-access article distributed under the terms and conditions of the Creative Commons Attribution license (http://creativecommons.org/licenses/by/4.0/). 